EVIDENCE BASED PUBLIC HEALTH POLICY AND PRACTICE

\title{
An outbreak of gastroenteritis from a non-chlorinated community water supply
}

\author{
M Kuusi, P Klemets, I Miettinen, I Laaksonen, H Sarkkinen, M L Hänninen, H Rautelin, E Kela, \\ J P Nuorti
}

J Epidemiol Community Health 2004;58:273-277. doi: 10.1136/jech.2003.009928

See end of article for authors' affiliations

Correspondence to:

Dr M Kuusi, Department of Infectious Disease Epidemiology, National Public Health Institute Mannerheimintie 166, 00300 Helsinki, Finland; markku.kuusi@ktl.fi

Accepted for publication 13 August 2003

Study objective: To determine the source and the extent of a community wide outbreak of gastroenteritis. Design: A matched case-control study with postal questionnaires. Subtyping of campylobacter strains by pulsed field gel electrophoresis (PFGE).

Setting: A rural municipality with a population of 8600 in southern Finland, August 2000. Two thirds of the population receive non-chlorinated ground water from the municipal water supply.

Participants: Cases were randomly selected among residents of the municipality who contacted the municipal health centre because of gastroenteritis and had illness onset between 31 July and 20 August 2000. Community controls were identified from the population registry and matched according to sex, year of birth, and postal code.

Main results: Four hundred and sixty three persons contacted the municipal health centre because of gastroenteritis. Campylobacter jejuni was isolated from stool samples of 24 persons. One hundred and thirty seven cases and 388 controls were enrolled in the case-control study. In multivariate analysis, drinking unboiled water from the municipal supply was significantly associated with illness (odds ratio $11.1,95 \%$ confidence interval 1.4 to 90.2). C jejuni was isolated from one tap water sample. The water isolate and all but one of the patient isolates were indistinguishable by PFGE.

Conclusions: Combining epidemiological investigation with molecular subtyping methods provided strong evidence that water was the source of the outbreak. Non-chlorinated small ground water systems may be susceptible to waterborne outbreaks and constitute a risk to rural populations.

\footnotetext{
C
} ampylobacters are the most commonly reported bacterial causes of gastroenteritis in most developed countries. ${ }^{1}$ Most campylobacter infections occur sporadically. Risk factors identified for sporadic campylobacter infections include drinking unpasteurised milk, drinking untreated water, eating chicken, barbecuing, and living or working on a farm. ${ }^{1-3}$ Campylobacter strains are traditionally classified by serotyping. Pulsed field gel electrophoresis (PFGE) has been shown to be a highly discriminatory method for campylobacter, and several PFGE patterns can be found within a serotype. ${ }^{4}$ PFGE has been useful in tracing back the source of outbreaks. ${ }^{56}$

Several community wide outbreaks resulting from contamination of public water systems with campylobacter have been reported..$^{6-12}$ In most outbreaks in which an epidemiological link to a contaminated community water supply was established, campylobacter was not isolated from the water. ${ }^{10}$ Few community wide outbreaks caused by ground well water have been described, ${ }^{611}{ }^{12}$ and in two of them, campylobacter was isolated from the water system. ${ }^{6}{ }^{12}$ In two outbreaks a cross connection between drinking and sewage water pipes has lead to contamination of the ground water system, ${ }^{6}{ }^{12}$ whereas in other outbreaks the exact mechanism of contamination has not been identified. ${ }^{911} 13$

In August 2000, a large outbreak of gastroenteritis occurred in a community in southern Finland. We conducted epidemiological, environmental, and microbiological investigations to determine the source and the extent of the outbreak and implemented control and preventive measures.

\section{METHODS}

\section{Outbreak}

Municipality A is located about $100 \mathrm{~km}$ north east from Helsinki in southern Finland. Two thirds (5500) of its 8600 population live in the centre. On 3 August, six patients with diarrhoea, abdominal pain, and fever contacted the municipal health centre. The environmental health unit was contacted, and samples from the non-chlorinated municipal water system were collected on 4 August. Initial results indicated no coliforms in the drinking water. During the next days, additional persons with gastrointestinal symptoms contacted the health centre, and had stool samples taken. On 9 August, $C$ jejuni was isolated from three patients. The next day, the National Public Health Institute (KTL) was notified of the outbreak. Interviews of initial patients suggested that the outbreak might be waterborne. Therefore, on 11 August, a boil water notice was issued and chlorination of the water supply system began on 12 August.

\section{Epidemiological investigation}

The municipal health centre collected information on all persons who contacted them by phone or visited the clinic because of gastrointestinal symptoms and who had illness onset between 25 July and 25 August. The line list included demographic data, and information about illness onset and symptoms.

We conducted a case-control study to determine the source of the outbreak. A case was defined as an illness with acute gastroenteritis defined as diarrhoea with at least three loose stools per 24 hours and/or vomiting and/or abdominal pain in a resident of municipality A between 31 July and 20 August. Of 250 eligible cases who contacted the health centre, a $50 \%$ sample was randomly selected to participate in the study. Only one person per household (the one with earliest onset of illness) was included. To include all patients from whom C jejuni was isolated, 12 additional case patients with positive stool cultures, but who were not part of the random sample, were included. Cases were excluded if they had travelled abroad within 10 days before the onset of illness. For each 
case, three community controls were randomly chosen from the population registry. Controls were matched to cases according to sex, year of birth, and postal code of residency. The case-control questionnaire was mailed to participants on 15 September. For children under 15 years of age, parents were asked to complete the questionnaire. Participants were asked about symptoms, treatments, consumption of water from various sources (tap water, well water, bottled water), and consumption of poultry, eggs, and unpasteurised milk products. For cases and matched controls, the questions referred to the two week period before the onset of symptoms in the case.

Mantel-Haenszel matched odds ratios (MORs) with 95\% confidence intervals for different water consumption categories and foods and $\chi^{2}$ for trend were calculated by using Epi-Info version 6.04 (Centers for Disease Control and Prevention (CDC), Atlanta). Multivariable analysis was performed by using SPSS 11.0 software (SPSS, Chicago, IL). To identify independent risk factors for campylobacteriosis, we used conditional logistic regression analysis. The full model included all variables associated with the illness at $\mathrm{p}<0.05$ in the univariate analysis. To determine the best model, we used backward elimination. The likelihood ratio test was used to assess the statistical significance of each variable. All reported $\mathrm{p}$ values are two tailed.

\section{Microbiological samples from patients}

Stool samples were obtained from 74 (16\%) of 463 patients who had gastrointestinal symptoms. The samples were analysed for the presence of salmonella, shigella, yersinia, campylobacter, aeromonas, and plesiomonas species by routine bacteriological methods. Stool samples were cultured for campylobacters by using selective media (Campylobacter Blood Free Selective medium: modified Charcoal Cefoperazone Deoxycholate Agar (mCCDA), LABM, Lancashire, UK) and confirmed as $C$ jejuni by Gram stain, and positive catalase, oxidase, and hippurate tests.

\section{Environmental investigation}

On 15 August, the municipal water system was investigated. For microbiological investigation, eight fresh water samples (three litres each) on 4 August and five (20 litres each) on 10 August were collected by trained personnel from various sites of the water supply system, including both ground water wells, water reservoirs, and tap water samples from households. Coliforms and campylobacters were identified from the water samples as described elsewhere. ${ }^{14}$ Briefly, 4-10 litres of water was filtrated through membranes of $0.45 \mu \mathrm{m}$ pore size and enriched in a Campylobacter Selective Enrichment Broth (Lab M, Bury, UK) or in Preston broth (Oxoid) at $42^{\circ} \mathrm{C}$ for 24 and 48 hours in a microaerobic atmosphere. A loopful of enrichment culture was spread onto mCCDA, Oxoid. Growth on mCCDA plates was confirmed as campylobacters by Gram strain and motility. API Campy (BioMerieux, France) and catalase tests were used for confirmation of $C$ jejuni.

\section{Serotyping and PFGE genotyping}

Sixteen $C$ jejuni isolates from case patients and one isolate recovered from tap water were serotyped with commercially available antisera (Campylobacter Antisera Seiken set, Denka Seiken, Japan) as described previously. ${ }^{15}$ Eight patient isolates and the water isolate were genotyped by PFGE using SmaI, SacII, and KpnI enzymes for digestion of DNA. ${ }^{16}$

\section{RESULTS}

\section{Epidemiological investigation}

Four hundred and sixty three persons who had gastroenteritis with illness onset between July 25 and August 25 contacted the health centre compared with the baseline of an average 20 monthly cases of gastroenteritis. Median age was 41 years (range 1-96 years), and 62\% were women. The epidemic curve (fig l) shows that the first patients became ill with gastroenteritis during the last days of July. On 4 August, the number of cases increased suddenly with peak incidence on 7 August. After 10 August cases began to decrease gradually and few were recorded after 20 August. The overall attack rate in the municipality according to the number of contacts to the health centre was $4.2 \%$.

The case-control study questionnaire was mailed to 137 cases and 388 controls. One hundred and thirteen cases (response rate, 84\%) and 287 controls (response rate, 74\%) completed the questionnaire. Of the 24 confirmed cases, 14 completed the questionnaire. Forty six controls were excluded from the analysis: 30 because of gastrointestinal symptoms, 10 were away from municipality A during the whole outbreak period, and six because of inadequately completed questionnaires. Thus, 241 controls were included in the analysis.

The median age of both cases and controls was 46 years (range 5-89), and 35\% were men. The symptoms were typical for campylobacter gastroenteritis, predominantly diarrhoea, and many cases had fever (table 1 ). The median duration of symptoms was six days (range $1-40$ ). Seventy six cases $(67 \%)$ were absent from work because of illness for a median of three days (range 1-30). Forty two cases (39\%) consulted a physician, and nine were hospitalised. Median duration of hospitalisation was 5.5 days (range 1-8). Treatment was prescribed to $38(34 \%)$ cases, and 27 (24\%) received antibiotics. Forty three $(41 \%)$ cases had other persons with gastroenteritis in the household during the outbreak period, compared with $29(12 \%)$ of 235 controls $(\mathrm{p}<0.001)$.

Of 113 case patients, 106 (94\%) reported having drunk unboiled tap water at home or outside the home during the two weeks before onset of illness compared with 140 (58\%) of 241 control subjects (MOR 20.9, 95\% CI 2.8 to 159.8). The drinking water used in the home, was unboiled tap water for $98(88 \%)$ cases and $130(57 \%)$ controls, and other types of water (boiled water, private well water, or bottled water) for $13(12 \%)$ cases and 98 (43\%) controls (MOR 6.9, 95\% CI 2.9 to 16.5). The odds of illness increased with increasing number of daily glasses of unboiled water consumed during the two week period suggesting a dose-response ( $p$ for trend $<0.001$, table 2 ). Drinking private well water, bottled water, and boiled water were all associated with decreased likelihood of illness. Of foods, the only significant association found was decreased likelihood of illness associated with consumption of eggs (table 3 ). In a conditional logistic regression model, the only variable that remained significantly associated with illness after adjustment for private well water, bottled water, boiled water, and eggs was drinking unboiled tap water (OR 11.1, 95\% CI 1.4 to 90.2, $\mathrm{p}=0.03)$.

\section{Environmental investigation}

The municipal water system had two ground water wells, which supplied water to the centre of the municipality. About $65 \%$ of the population received water from the municipal supply, the rest lived outside of the centre and had private wells. Well A was constructed in the 1950s and produced $200 \mathrm{~m}^{3} /$ day, and well B was constructed in the 1970s and produced $800 \mathrm{~m}^{3} /$ day. Water from the ground wells was pumped to two water reservoirs $\left(400 \mathrm{~m}^{3}\right.$ and $\left.1300 \mathrm{~m}^{3}\right)$, both of which received water from both wells. From the reservoirs, the water was distributed to households. Water temperature measured at well B was $7.6^{\circ} \mathrm{C}$. The water was not routinely chlorinated, and only sodium bicarbonate was added to regulate $\mathrm{pH}$. Water quality was routinely tested monthly for coliforms. These tests had not yielded any positive findings 


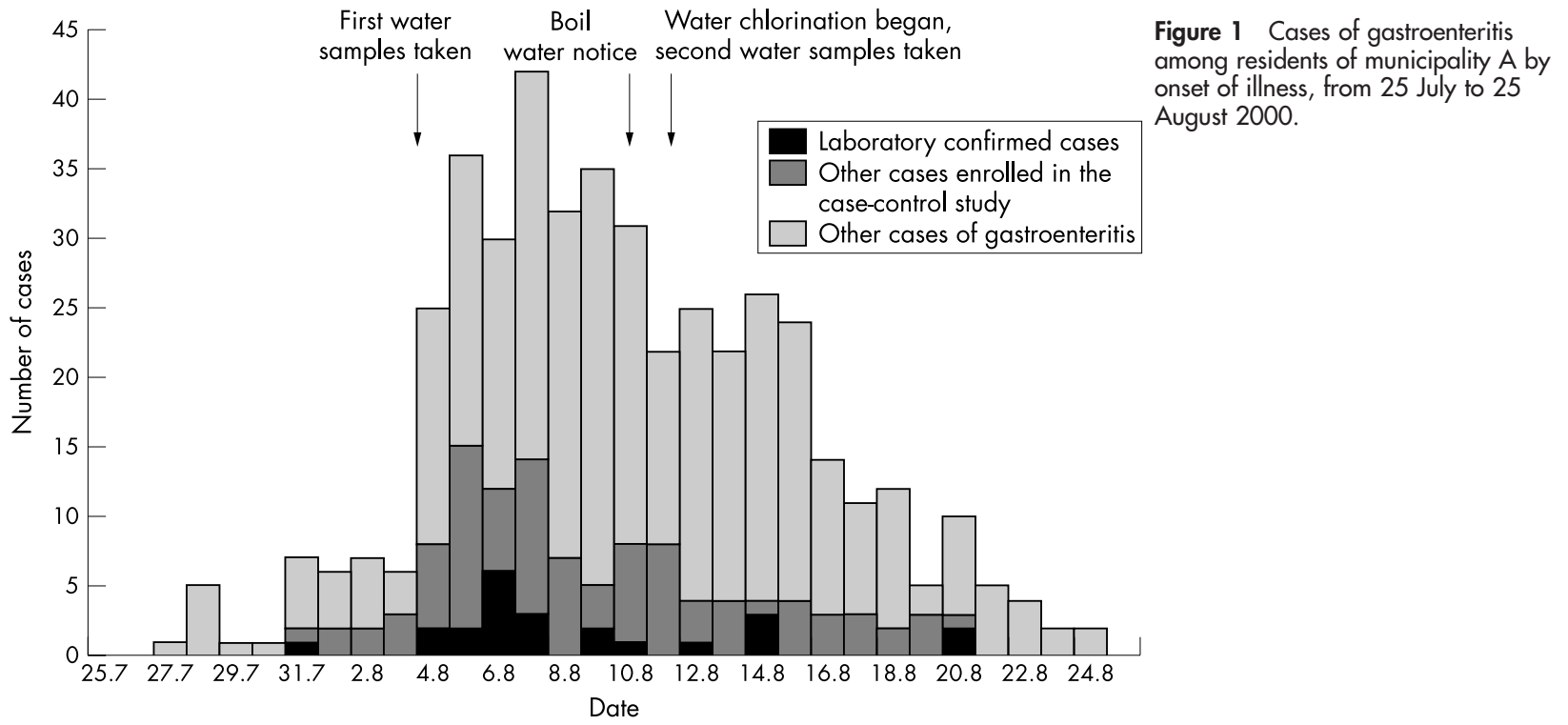

before the outbreak. No construction or cleaning works of the water system had been carried out during the year 2000.

Both ground water wells were located outside the centre of municipality about 30 metres away from a large lake. The houses close to well A were connected to the municipal sewage system, whereas the vacation houses close to well B were not. There was no farming activity in the vicinity of the wells. A dry toilet, and a compost heap for household wastes were located about 15 metres from well B. Well B was built on a landfill of poor quality. The wells were not fenced, allowing people and animals access to the area. Water reservoirs were accessible to anyone, and the lock in the door of the smaller reservoir was broken. According to the National Weather Service, the total rainfall in this area in July 2000 was 104 mm compared with 58 mm in July 1999. The heaviest rains occurred between 22 July and 25 July.

\section{Microbiological samples from patients and water} $C$ jejuni was cultured from 24 (32\%) of 74 stool samples submitted for examination from patients with gastroenteritis. No other pathogens were isolated. C jejuni was recovered from one tap water sample collected on 10 August at a day care centre. No coliforms were isolated from water samples.

\section{Typing of bacterial isolates from patients and the environment}

Sixteen $C$ jejuni isolates from patients were serotyped and eight subtyped by PFGE. All 16 were serotype Penner 12, and seven had indistinguishable SacII and KpnI PFGE patterns. SmaI patterns had only four fragments and they were all identical (results not shown). The isolate from water was also

Table 1 Symptoms among 113 case patients with gastroenteritis enrolled in the case-control study, Finland, August, 2000

\begin{tabular}{lll}
\hline Symptom & $\begin{array}{l}\text { Case patients in case-control } \\
\text { study }\end{array}$ & $\%$ \\
\hline Diarrhoea & 101 of 106 & 95 \\
Bloody diarrhoea & 3 of 83 & 4 \\
Abdominal pain & 96 of 108 & 89 \\
Nausea & 74 of 97 & 76 \\
Fever & 60 of 96 & 63 \\
Vomiting & 32 of 88 & 36 \\
\hline
\end{tabular}

serotype Penner 12 and the PFGE pattern was indistinguishable from the seven patient strains (fig 2). The patient strain with a different pattern had three additional bands. During May to July 2000, 17 C jejuni strains were identified in the Central Hospital laboratory serving the whole area of PäijätHäme, including municipality A. Only one of these strains was the same serotype as the outbreak strain.

\section{DISCUSSION}

On the basis of evidence from epidemiological and microbiological investigations, this campylobacter outbreak was caused by contaminated municipal water supply. In the casecontrol study, illness was significantly associated with drinking unboiled tap water. Indistinguishable strains of $C$ jejuni by serotyping and PFGE were recovered from both patients and the non-chlorinated municipal water system. Isolation of the microbe from both the water and the patients, and finding an association between consumption of municipal tap water and illness in an analytical study, provides strong evidence that the outbreak was waterborne. ${ }^{17}$

Although the exact mechanism for contamination remained unknown, investigation of the water system suggested several possibilities. As shown previously, weather conditions may have been an important contributing factor. $^{6}{ }^{18}$ July 2000 was very rainy and the hydraulic conductivity of the soil was high. Heavy rainfalls could have resulted into infiltration of bacteria from human or animal faeces through the soil into ground water. The compost heap and dry toilet close to well B clearly were a hazard for contamination of the well. As the lake's water surface rises during heavy rainfalls, infiltration to ground water may increase. Water from wells A and B contained organic material indicating infiltration of lake water into ground water. Seagulls and other birds are often carriers of campylobacter, ${ }^{19}$ and their faeces may contaminate surface waters, including lake water. However, substantial contamination with a single campylobacter strain from bird faeces would be very unlikely.

Although community wide waterborne outbreaks caused by campylobacter have been reported previously, the bacteria has rarely been isolated from ground water systems. ${ }^{6}{ }^{12}$ The concentration of campylobacter in the water may be low and the strains, although remaining viable, may lose their culturability with time, ${ }^{20}$ making isolation difficult. The water source may be contaminated intermittently, or for a short period. Samples are therefore often taken too late. 
Table 2 Dose-response relation between average daily consumption of unboiled tap water and odds of gastroenteritis

\begin{tabular}{lllll}
\hline Glasses of unboiled tap water/day & $\begin{array}{l}\text { Case } n=101 \\
(\%)^{*}\end{array}$ & $\begin{array}{l}\text { Control } \mathbf{n = 1 2 1} \\
(\%)^{*}\end{array}$ & Matched OR & $95 \% \mathbf{C l}$ \\
\hline $0-2$ & $9(9)$ & $43(35)$ & Ref & - \\
$3-4$ & $23(23)$ & $32(26)$ & 1.4 & 0.2 to 9.5 \\
$5-6$ & $28(28)$ & $29(24)$ & 3.9 & 1.1 to 22.5 \\
$>7$ & $41(41)$ & $18(15)$ & 12.3 & 1.9 to 552.4 \\
\hline *Data regarding daily consumption of unboiled tap water were not available for 12 cases and 120 controls.
\end{tabular}

Table 3 Consumption of drinking water and selected foods among case patients with gastroenteritis and among age, sex, and residence matched controls, Finland, August, 2000

\begin{tabular}{|c|c|c|c|c|c|c|c|}
\hline Exposure & $\begin{array}{l}\text { Cases* }^{*} \\
(n=113)\end{array}$ & $\%$ & $\begin{array}{l}\text { Controls* } \\
(n=241)\end{array}$ & $\%$ & Matched OR & $95 \% \mathrm{Cl}$ & p Value \\
\hline \multicolumn{8}{|l|}{ Drinking water } \\
\hline Unboiled tap water & 106 of 108 & 98 & 140 of 209 & 67 & 20.9 & 2.8 to 154.8 & 0.003 \\
\hline Private well water & 16 of 80 & 20 & 71 of 159 & 45 & 0.2 & 0.1 to 0.6 & 0.001 \\
\hline Bottled water & 16 of 76 & 21 & $66 / 151$ & 56 & 0.3 & 0.1 to 0.8 & 0.006 \\
\hline Boiled water & 23 of 79 & 29 & 109 of 172 & 63 & 0.2 & 0.1 to 0.5 & $<0.001$ \\
\hline $\begin{array}{l}\text { Other drinking water } \\
\text { Food products }\end{array}$ & 17 of 73 & 23 & 44 of 132 & 33 & 0.8 & 0.4 to 1.8 & 0.56 \\
\hline Chicken & 50 of 97 & 51 & 148 of 213 & 70 & 0.5 & 0.3 to 1.0 & \multirow{4}{*}{$\begin{array}{l}0.05 \\
0.02 \\
0.24 \\
0.38\end{array}$} \\
\hline Eggs & 62 of 95 & 65 & 179 of 224 & 80 & 0.5 & 0.3 to 0.9 & \\
\hline Turkey & 10 of 94 & 11 & 26 of 189 & 14 & 0.6 & 0.3 to 1.4 & \\
\hline $\begin{array}{l}\text { Unpasteurised milk } \\
\text { products }\end{array}$ & 11 of 97 & 11 & 32 of 204 & 16 & 0.7 & 0.3 to 1.6 & \\
\hline
\end{tabular}

The outbreak continued for more than two weeks, and the epidemic curve suggests that the water system was contaminated with campylobacter for several days. As the incubation period of campylobacter ranges from two to seven days, all cases were probably not infected simultaneously. However, it is possible that there was no continuous source of campylobacter, but after incidental contamination, campylobacter persisted in the water system for several days. The temperature of water in the municipal system was favourable for survival of campylobacter, which can survive in cold water for several weeks. ${ }^{21}$ As only one campylobacter strain was

$$
\text { Kpnl Sacll }
$$

$\begin{array}{llllllllllllllllll}1 & 2 & 3 & 4 & 5 & 6 & 7 & 8 & 9 & 1 & 2 & 3 & 4 & 5 & 6 & 7 & 8 & 9\end{array}$

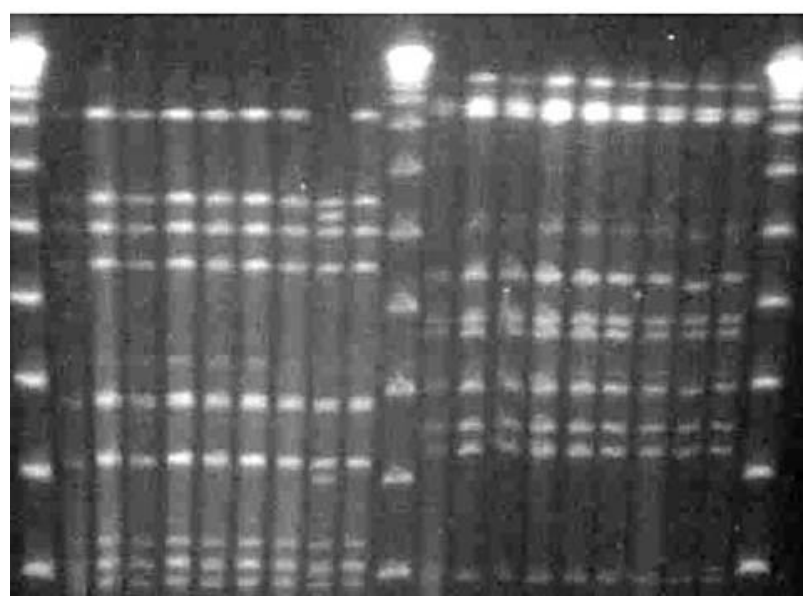

Figure 2 Sadl and Kpnl pulsed field gel electrophoresis patterns of Campylobacter jejuni isolates from patients and water. Patients: lanes 1 to 6 and 8 to 9 , water from the municipal system: lane 7 . detected among patients, repeated contamination was unlikely. This would have been expected to lead to contamination with several bacterial strains. ${ }^{13}$

Our investigation illustrates the power of combining epidemiological data with molecular subtyping methods. PFGE has previously been used for tracing back the source in outbreaks associated with food handler contamination, ${ }^{5}$ and consumption of unpasteurised milk. ${ }^{4}$ In this outbreak, PFGE was an effective tool for subtyping campylobacter. The strains from both the water and patients were indistinguishable by PFGE confirming that cases in the community were related and linked to water. ${ }^{6}$ The outbreak strain, Penner serotype 12 is one of the most common serotypes causing domestically acquired infections in Finland, and it has frequently been found in chickens. ${ }^{22}$ One isolate from patients showed slightly different SacII and KpnI PFGE patterns suggesting either a genomic recombination or point mutations. These results show how the genotype of human $C$ jejuni strains may change in natural infections, a phenomenon that has been shown in strains isolated from chickens. ${ }^{23} 24$

Response rates among both cases and controls were high, and therefore non-response bias probably did not affect the results of the case control study. The time interval between the outbreak and mailing the questionnaire was rather short reducing the likelihood of recall bias. Our case definition may have included persons with gastroenteritis caused by other infectious agents. This non-differential misclassification may have biased our findings towards the null. Missing values, which are difficult to avoid in postal studies, were common in returned questionnaires. Because of them, matched analysis for only confirmed cases did not have sufficient power to show statistical significance. Controls were from the same postal code area as cases, and mostly had the same source of household water, leading to risk of overmatching with possible underestimation of drinking water as risk factor. Because of the boil water notice, cases and controls were aware that municipal tap water was the suspected source of 


\section{Key points}

- In waterborne outbreaks Campylobacter jejuni has rarely been isolated from community water systems.

- Subtyping of campylobacter strains by PFGE was useful in confirming the source of the outbreak.

- This study provided strong epidemiological and microbiological evidence that non-chlorinated ground well water was the source of a community wide campylobacter outbreak.

- Non-chlorinated ground water systems may be susceptible to waterborne outbreaks and constitute a risk to rural populations that could be reduced by chlorination or ultraviolet irradiation of ground water.

the outbreak. This may have biased our results, because cases may have been sensitised to the suspected risk factor while controls have underestimated it. Only $38 \%$ of persons who contacted the health centre and $35 \%$ of the case-control study participants were men. This difference between sexes has not been reported in previous outbreaks, and may reflect a lower threshold for women to seek care because of gastrointestinal symptoms.

This outbreak highlights campylobacter as an important waterborne pathogen. The outbreak caused considerable morbidity, and direct and indirect costs because of consultations, treatments, and loss of productivity. Of controls, 10.6\% had to be excluded because of gastrointestinal symptoms. Assuming they were representative of the whole population, about 900 persons fell ill during the outbreak. Serious systemic illness caused by campylobacter occurs rarely but can occasionally lead to septicaemia and death. ${ }^{25}$ In previous outbreaks, the occurrence of reactive arthritis after campylobacter infection has varied between $0.7 \%$ and $1.8 \%{ }^{26}{ }^{27}$ The risk of Guillain-Barré syndrome is $<1$ per 1000 C jejuni infections. ${ }^{25}$

Ground water has been regarded as a safe source of drinking water, and unlike surface water it is therefore usually not disinfected before distribution. Apart from Finland, ground water is an important source of drinking water in many other European countries and North America. In Finland, about half of the population obtains drinking water produced by public ground water systems, which usually serve small communities with less than 500 consumers. ${ }^{28}$ Since 1998, four community wide campylobacter outbreaks in Finland have been caused by ground well water systems. ${ }^{14}$ The safety of these systems should clearly be improved, including construction of new ground water wells, sterilisation of water with ultraviolet light, or routine chlorination of the water to prevent further outbreaks.

\section{ACKNOWLEDGEMENTS}

We thank Anja Siitonen from the Laboratory of Enteric Pathogens of KTL and Merja Kulonen and Pekka Hakala from the Environmental Health Unit of Asikkala Municipality for their valuable work in this outbreak investigation. We also thank Outi Lyytikäinen and Petri Ruutu from the Department of Infectious Disease Epidemiology of KTL for constructive comments on the manuscript, and Jukka Ollgren from KTL for statistical advice.

\section{Authors' affiliations}

M Kuusi, P Klemets, E Kela, J P Nuorti, Department of Infectious Disease Epidemiology, National Public Health Institute, Helsinki, Finland I Miettinen, Department of Environmental Health, National Public Health Institute, Kuopio, Finland

I Laaksonen, Municipal Health Centre, Asikkala, Finland
H Sarkkinen, Department of Clinical Microbiology, Central Hospital of Päiiät-Häme, Lahti, Finland

M L Hänninen, Department of Food and Environmental Hygiene, Faculty of Veterinary Medicine, University of Helsinki, Finland

H Rautelin, Department of Bacteriology and Immunology, Haartman Institute, University of Helsinki and Helsinki University Central Hospital Laboratory Diagnostics

Funding: none

Conflicts of interest: none declared.

\section{REFERENCES}

1 Friedman CR, Neimann J, Wegener HC, et al. Epidemiology of Campylobacter jejuni infections in the United States and other industrialized nations. In: Nachamkin I, Blaser MJ, eds. Campylobacter. 2nd edn. Washington DC: American Society for Microbiology, 2000:3-26.

2 Kapperud G, Skjerve E, Bean NH, et al. Risk factors for sporadic campylobacter infections: results of a case-control study in southeastern Norway. J Clin Microbiol 1992;30:3117-21.

3 Studahl A, Andersson Y. Risk factors for indigenous campylobacter infection: a Swedish case-control study. Epidemiol Infect 2000;125:269-75.

4 Lehner A, Schneck C, Feierl G, et al. Epidemiologic application of pulsed-field gel electrophoresis to an outbreak of Campylobacter jejuni in an Austrian youth centre. Epidemiol Infect 2000;125:13-16.

5 Olsen SJ, Hansen GR, Bartlett L, et al. An outbreak of Campylobacter jejuni infections associated with food handler contamination: the use of pulsed-field gel electrophoresis. J Infect Dis 2001;183:164-7.

6 Engberg J, Gerner-Smidt P, Scheutz F, et al. Water-borne Campylobacter jejuni infection in a Danish town-a 6-week continuous source outbreak. Clin Microbiol Infect 1998;4:648-56.

7 Vogt RL, Sours HE, Barrett T, et al. Campylobacter enteritis associated with contaminated water. Ann Intern Med 1982;96:292-6.

8 Palmer SR, White JM, Gully PR, et al. Water-borne outbreak of campylobacter enteritis. Lancet 1983;i:287-90.

9 Mentzing LO. Waterborne outbreaks of campylobacter enteritis in central Sweden. Lancet 1981 ;ii:352-4.

10 Melby K, Gondrosen B, Gregusson S, et al. Waterborne campylobacteriosis in northern Norway. Int J Food Microbiol 1991;12:151-6.

11 Sacks JJ, Lieb S, Baldy LM, et al. Epidemic campylobacteriosis associated with a community water supply. Am J Public Health 1986;76:424-9.

12 Rautelin H, Koota K, von Essen R, et al. Waterborne Campylobacter jejuni epidemic in a Finnish hospital for rheumatic diseases. Scand J Infect Dis 1990;22:321-6.

13 Millson M, Bokhout M, Carlson J, et al. An outbreak of Campylobacter jejuni gastroenteritis linked to meltwater contamination of a municipal well. Can J Public Health 1991:82:27-31.

14 Hänninen ML, Haajanen H, Pummi T, et al. Detection and typing of Campylobacter jejuni and analysis of indicator organisms in three waterborne outbreaks in Finland. Appl Environ Microbiol 2003;69:1391-6.

15 Rautelin H, Hänninen ML. Comparison of a commercial test for serotyping heat-stable antigens of Campylobacter jejuni with genotyping by pulsed-field gel electrophoresis. J Med Microbiol 1999;48:617-21

16 Hänninen ML, Perko-Mäkelä P, Rautelin H, et al. Genomic relatedness within five common Finnish Campylobacter jejuni pulsed-field gel electrophoresis genotypes studied by amplified fragment length polymorphism analysis, ribotyping, and serotyping. Appl Environ Microbiol 2001;67:1581-6.

17 Tillett HE, de Louvois J, Wall PG. Surveillance of outbreaks of waterborne disease: categorizing levels of evidence. Epidemiol Infect 1998;120:37-42.

18 Anonymous. Waterborne outbreak of gastroenteritis associated with a contaminated municipal water supply, Walkerton, Ontario, May-June 2000. Can Comm Dis Rep 2000;26:170-3

19 Broman T, Palmgren H, Bergström S, et al. Campylobacter jejuni in blackheaded gulls (Larus ridibundulus): prevalence, genotypes, and influence on C jejuni epidemiology. J Clin Microbiol 2002;40:4594-602.

20 Thomas C, Hill DJ, Mabey M. Evaluation of the effect of temperature and nutrients on the survival of Campylobacter spp in water microcosms. J Appl Microbiol 1999:86:1024-32.

21 Blaser MJ, Hardesty HL, Powers B, et al. Survival of Campylobacter fetus subsp jejuni in biological milieus. J Clin Microbiol 1980;11:309-13.

22 Hänninen ML, Perko-Mäkelä $P$, Pitkälä $A$, et al. A three-year study of Campylobacter jejuni genotypes in humans with domestically acquired infections and in chicken samples from the Helsinki area. J Clin Microbiol 2000;38: 1998-2000

23 Wassenaar TM, Geilhausen B, Newell DG. Evidence of genomic instability in Campylobacter jejuni isolated from poultry. Appl Environ Microbiol 1998:64:1816-21.

24 De Boer P, Wagenaar JP, Achterberg RP, et al. Generation of Campylobacter jejuni genetic diversity in vivo. Mol Microbiol 2002;44:351-9.

25 Allos BM. Campylobacter jejuni infections: update on emerging issues and trends. Clin Infect Dis 2001;32:1201-6.

26 Eastmond CJ, Norris Rennie JA, Reid TMS. An outbreak of Campylobacter enteritis-a rheumatological followup survey. J Rheumatol 1983;10:107-8.

27 Bremell T, Bjelle A, Svedhem A. Rheumatic symptoms following an outbreak of Campylobacter enteritis: a five year follow up. Ann Rheum Dis 1991;50:934-8.

28 Miettinen IT, Zacheus $\mathrm{O}$, von Bonsdorff $\mathrm{CH}$, et al. Waterborne epidemics in Finland in 1998-1999. Wat Sci Tech 2001;43:67-71 